\title{
PROTEINPOLYSACCHARIDES OF HUMAN COSTAL CARTILAGE *
}

\author{
By BLANCHE JOHNSON AND MAXWELL SCHUBERT \\ (From the Department of Medicine and the Rheumatic Diseases Study Group, New York Uni- \\ versity School of Medicine, New York, N. Y.)
}

(Submitted for publication June 17, 1960 ; accepted July 15, 1960)

From bovine nasal cartilage a product has been isolated which seemed to behave as a compound and which contained chondroitin sulfate and protein; this product was called chondromucoprotein (1). In similar work with human costal cartilage, greater difficulty was encountered. Although a somewhat analogous product was isolated, its characterization as a chemical entity was far less satisfactory, since its composition seemed to vary rather widely in the proportions of protein and polysaccharide present in samples prepared from the cartilage of different individuals. Bovine nasal chondromucoprotein, during the course of many scores of preparations, seemed to be constant in composition. Recently it was found that bovine nasal chondromucoprotein could be fractionated centrifugally to give two distinct products, each consisting of both protein and polysaccharide (2). These products were called proteinpolysaccharides and were distinguished as heavy and light, depending upon their sedimentation properties. They were referred to as $\mathrm{PP}-\mathrm{H}$ and $\mathrm{PP}-\mathrm{L}$, and were found to consist of very different proportions of protein and polysaccharide. The present report describes the isolation from human costal cartilage of a crude product analogous to bovine nasal chondromucoprotein, describes attempts to arrive at products of constant composition by repeated reprecipitation, and then describes the ultracentrifugal separation of the crude material into two fractions analogous to the PP-H and PP-L of bovine nasal cartilage but not identical with them.

Since use of the word mucoprotein is to be discontinued it will be best to discontinue use of the word chondromucoprotein also and to refer to the product it described as a crude proteinpolysaccharide (crude PP). Where it is necessary to distinguish between products isolated from bovine nasal cartilage and those isolated from human cos-

* The work reported has had the support of United States Public Health Service, Grants A28(C8) and A1431 (C3). tal cartilage, the letters $\mathrm{BN}$ or $\mathrm{HC}$ will be set befor the product. Then the products separated from crude HC-PP by ultracentrifugation can be called HC-PP-L and HC-PP-H.

\section{EXPERIMENTAL METHODS}

Extraction procedure. Human costal cartilage was collected about 24 to 48 hours after death and cleaned in a cold room to remove all noncartilaginous tissue. It was diced into pieces about $6 \mathrm{~mm}$ on a side and all grossly calcified pieces were discarded. Weighed samples were dried by beating about $15 \mathrm{~g}$ at a time in a Waring blendor with ethanol $(250 \mathrm{ml})$ for 3 minutes in a cold room. The finely shredded product was transferred to a centrifuge cup, washed by centrifuging with ethanol and absolute ether and dried in vacuo. In columns 3,4 and 5 of Table I are values for the dry weights as fractions of the wet weights, and the nitrogen and hexosamine (against glucosamine as standard) contents of the dried samples from 19 individuals varying in age from 7 to 74 years. There are no obvious differences in the dry weights or in the nitrogen contents with either sex or age. A possible trend in hexosamine content with age is suggested, since all values above 7 per cent occur at ages less than 34 and all values below 6 per cent occur at ages over 56 .

After preliminary experiments had shown that a crude HC-PP could be extracted from human rib cartilage, it seemed desirable to learn whether it could be extracted as readily from alcohol-dried cartilage as from fresh wet cartilage, since this knowledge would facilitate further comparative studies. Each of the fresh wet cartilage samples represented in Table I was divided into two parts; one part was worked up directly to extract the crude HC-PP from the fresh wet cartilage, the second part was first dried as described above and then worked up to extract its crude HC-PP.

All extraction operations were run in a cold room at $5^{\circ} \mathrm{C}$. For each extraction an amount of cartilage was used corresponding to 10 to $20 \mathrm{~g}$ of dry cartilage. When wet cartilage was used, yields were calculated on the basis of the dry cartilage weight as given in column 3 of Table I. Either dried cartilage $(4 \mathrm{~g})$ or fresh wet cartilage $(8 \mathrm{~g})$ was beaten with water $(280 \mathrm{ml})$ in a VirTis-45 homogenizer at its top speed for 30 minutes in a flask $(500 \mathrm{ml})$ with baffles set in an ice bath. To the creamy homogenate was added ethanol $(560 \mathrm{ml})$ and the mixture was centrifuged $(4,700 \mathrm{rpm})$ for one-half hour. The supernatant solution was filtered through a 
TABLE I

Data on human costal cartilage and the crude HC-PP isolated from it *

\begin{tabular}{|c|c|c|c|c|c|c|c|c|c|c|}
\hline \multirow[b]{2}{*}{ Age } & \multirow[b]{2}{*}{ Sex } & \multicolumn{3}{|c|}{ Cartilage } & \multicolumn{3}{|c|}{$\begin{array}{l}\text { Crude HC-PP from fresh } \\
\text { wet cartilage }\end{array}$} & \multicolumn{3}{|c|}{$\begin{array}{c}\text { Crude HC-PP from } \\
\text { dried cartilage }\end{array}$} \\
\hline & & $\frac{\text { Dry wt }}{\text { Wet wt }}$ & $\mathbf{N}$ & $\begin{array}{l}\text { Hexos- } \\
\text { amine }\end{array}$ & Yield & $\mathbf{N}$ & $\begin{array}{l}\text { Hexos- } \\
\text { amine }\end{array}$ & Yield & $\mathbf{N}$ & $\begin{array}{l}\text { Hexos- } \\
\text { amine }\end{array}$ \\
\hline$y r s$ & & & $\%$ & $\%$ & $\mathrm{~g} / \mathrm{g}$ cartilage & $\%$ & $\%$ & $\mathrm{~g} / \mathrm{g}$ cartilage & $\%$ & $\%$ \\
\hline 7 & $\mathbf{M}$ & 0.38 & 12.3 & 6.20 & 0.15 & 5.80 & 14.8 & 0.14 & 5.10 & 14.4 \\
\hline 20 & $\mathrm{~F}$ & 0.51 & & & 0.14 & 7.20 & 14.0 & 0.25 & 7.30 & 14.1 \\
\hline 21 & $\mathrm{~F}$ & 0.37 & 10.8 & 6.60 & 0.28 & 6.76 & 13.3 & 0.22 & 5.80 & $\begin{array}{l}13.1 \\
13.8\end{array}$ \\
\hline 21 & $\mathrm{M}$ & 0.41 & 12.2 & 7.55 & 0.23 & 7.38 & 15.5 & 0.28 & 6.80 & $\begin{array}{l}12.0 \\
14.7\end{array}$ \\
\hline 25 & $F$ & 0.46 & 11.1 & 8.67 & 0.19 & 7,74 & 10.4 & 0.25 & 7.90 & 12.8 \\
\hline 31 & M & 0.36 & 11.5 & 7.32 & 0.28 & 7.85 & 14.1 & 0.21 & 8.00 & 13.8 \\
\hline 34 & $\mathrm{M}$ & 0.44 & 12.1 & 6.88 & 0.24 & 8.41 & 12.1 & 0.20 & 9.20 & 11.6 \\
\hline 36 & $\mathbf{M}$ & 0.32 & 12.0 & 6.86 & 0.29 & 8.65 & 11.5 & 0.18 & 9.46 & 11.7 \\
\hline 36 & $\mathrm{~F}$ & 0.43 & 10.9 & 6.90 & 0.22 & 9.30 & 12.0 & 0.21 & 9.30 & 12.0 \\
\hline 40 & $\mathrm{~F}$ & 0.51 & & 6.04 & 0.14 & 8.71 & 11.1 & 0.12 & 9.60 & 12.2 \\
\hline 43 & $\mathrm{~F}$ & 0.48 & 12.2 & 6.10 & 0.21 & 8.20 & 11.2 & 0.17 & 8.60 & 10.7 \\
\hline 43 & $F$ & 0.44 & 11.7 & 6.75 & 0.17 & 9.20 & 12.1 & 0.23 & 9.06 & 10.8 \\
\hline 44 & $\mathrm{~F}$ & 0.44 & 11.5 & 6.95 & 0.23 & 8.53 & 11.2 & 0.21 & 9.01 & 11.2 \\
\hline 45 & $\mathrm{M}$ & 0.41 & 10.0 & 6.80 & 0.26 & 6.07 & 10.1 & 0.27 & 8.84 & 10.2 \\
\hline 56 & $\mathbf{M}$ & 0.45 & & 6.01 & 0.27 & 9.20 & 10.4 & 0.24 & 9.60 & 10.4 \\
\hline 59 & $\mathrm{~F}$ & 0.40 & 11.4 & 5.54 & 0.23 & 9.01 & 8.5 & 0.17 & 9.30 & 9.9 \\
\hline 64 & M & 0.46 & 10.8 & 4.80 & 0.13 & 8.29 & 9.2 & 0.18 & 9.56 & 9.5 \\
\hline 69 & $\mathbf{M}$ & 0.40 & 11.7 & 5.45 & 0.21 & 9.62 & 9.5 & 0.20 & 10.10 & 8.6 \\
\hline 74 & $\mathbf{M}$ & 0.58 & 11.9 & 5.72 & 0.13 & 8.83 & 8.8 & 0.22 & 9.34 & 8.4 \\
\hline \multicolumn{2}{|l|}{ Average } & 0.43 & & & 0.21 & & & 0.21 & & \\
\hline \multicolumn{2}{|c|}{$\begin{array}{l}\text { Bovine coastal } \\
\text { cartilage }\end{array}$} & 0.38 & 8.2 & 5.5 & & & & 0.17 & 5.7 & 16.0 \\
\hline \multirow{2}{*}{\multicolumn{2}{|c|}{$\begin{array}{l}\text { Bovine nasal } \\
\text { cartilage }\end{array}$}} & & & & & & & & & \\
\hline & & 0.24 & 8.3 & 9.4 & & & & 0.35 & 5.2 & 17.1 \\
\hline
\end{tabular}

* See first page of text for definitions.

plug of glass wool. The residue at this stage is called $R$ and is referred to later. It may be dried with alcohol and ether. The filtered extract was opalescent, and on addition of potassium acetate ( 1 per cent, wt/vol) produced a flocculent precipitate, the crude HC-PP. It was centrifuged and washed with ethanol and ethyl ether and dried in vacuum. Combined yields of the cartilage residue and crude HC-PP amounted to 90 to 95 per cent of the dry weight of the cartilage used.

In Table I, columns 6 and 9 give the yield of crude HC-PP from the fresh wet and from the alcohol-dried cartilage, columns 7 and 10 give their nitrogen content, and columns 8 and 11 give their hexosamine content (against glucosamine as standard). Although there are often great differences in the yield of the product from the wet and the dry cartilage, these seem to be chance fluctuations and the average yields of the product from wet and dry cartilage are identical, 21 per cent of the dry weight of the cartilage used. This is about two-thirds the amount of BN-PP isolated from bovine nasal cartilage by the same procedure. It seems clear that, as with bovine nasal cartilage, drying the human costal cartilage with ethanol before extraction with water makes no difference in the yield of crude HC-PP obtainable. Nor does drying seem to affect the average hexosamine content of the crude products. Nitrogen values of crude products from dried cartilage average slightly higher than those from fresh wet cartilage, but this is probably not significant. The spread of values for both nitrogen and hexosamine content is higher than the spread in corresponding values for BN-PP (1). As with the hexosamine content of the whole cartilage (column 5 of Table I), there seems to be a trend of the hexosamine content of the crude HC-PP to decrease with age (columns 8 and 11). All hexosamine values over 12 per cent occur in products from individuals at ages below 34 and all hexosamine values below 10 per cent occur in products from individuals at ages over 56.

At the bottom of Table I are two rows of figures included for comparative purposes, giving data on bovine cartilage (BC), both costal and nasal, and on the crude $\mathrm{BC}-\mathrm{PP}$ and $\mathrm{BN}-\mathrm{PP}$ isolated from them by the same procedure as that described above. It appears that only in the youngest age range does the crude HC-PP approach in composition that of the crude $\mathrm{BC}-\mathrm{PP}$ or the crude BN-PP.

Reprecipitation procedure. It seemed possible that the fluctuations and the apparent trend in composition with age of the crude HC-PP might be associated with protein impurities. Attempts were made to purify the crude HC-PP by reprecipitation. Each of the samples of crude HC-PP was dissolved in water (about $1 \mathrm{~g}$ per 100 $\mathrm{ml}$ ), any insoluble material was removed by centrifugation, and the proteinpolysaccharide in solution was reprecipitated by addition of potassium acetate to about 2 per cent (wt/vol) and of ethanol to 70 per cent (vol/ 
TABLE II

Data on crude and reprecipitated $H C$-PP isolated from human costal cartilage of subjects in the age ranges shown*

\begin{tabular}{|c|c|c|c|c|c|c|c|c|c|}
\hline & \multicolumn{3}{|c|}{ Crude HC-PP } & \multicolumn{3}{|c|}{ HC-PP once reprecipitated } & \multicolumn{3}{|c|}{$\begin{array}{l}\text { HC-PP; ratios, } \frac{\text { nitrogen }}{\text { hexosamine }} \\
\text { after successive } \\
\text { reprecipitations }\end{array}$} \\
\hline & Yield & $\mathbf{N}$ & $\begin{array}{c}\text { Hexos- } \\
\text { amine }\end{array}$ & Yield & $\mathbf{N}$ & $\begin{array}{l}\text { Hexos- } \\
\text { amine }\end{array}$ & Once & Twice & Thrice \\
\hline yrs & $\mathrm{g} / \mathrm{g}$ cartilage & $\%$ & $\%$ & $\begin{array}{c}g / g \text { crude } \\
H C-P P\end{array}$ & $\%$ & $\%$ & & & \\
\hline $\begin{array}{c}7-31 \\
34-56 \\
59-74 \\
\text { Bovine nasal } \\
\text { cartilage }\end{array}$ & $\begin{array}{l}0.22 \\
0.22 \\
0.19 \\
0.35\end{array}$ & $\begin{array}{l}7.0 \\
8.8 \\
9.2 \\
5.2\end{array}$ & $\begin{array}{r}13.8 \\
11.3 \\
9.1 \\
17.1\end{array}$ & $\begin{array}{l}0.74 \\
0.61 \\
0.36 \\
0.90\end{array}$ & $\begin{array}{l}6.7 \\
8.1 \\
7.9 \\
5.3\end{array}$ & $\begin{array}{l}14.3 \\
12.9 \\
13.5 \\
17.4\end{array}$ & $\begin{array}{l}5.9 \\
8.0 \\
7.4 \\
3.9\end{array}$ & $\begin{array}{l}5.0 \\
7.4 \\
7.7 \\
3.9\end{array}$ & $\begin{array}{l}5.4 \\
7.7 \\
7.8 \\
3.9\end{array}$ \\
\hline
\end{tabular}

* See first page of text for abbreviations.

vol). The reprecipitated product was washed with ethanol and ether, dried, weighed, and analyzed. Table II (columns 5, 6 and 7) summarizes the results, which are given as average yields and as average nitrogen and hexosmaine percentages within each of the age ranges indicated in column 1. The reason for this is that in a number of cases samples were pooled in order to get enough material for the successive reprecipitations. Pooling was done only with samples within 4 years of each other. In columns 2, 3 and 4 are given for comparison the average values of yield, and nitrogen and hexosamine content of the crude HC-PP, already described in Table I and averaged for each of the three age groups indicated in column 1, Table II. Column 5 gives the average yields of the once-reprecipitated HC-PP, and columns 6 and 7 give its nitrogen and hexosamine contents. It is apparent that with advance in age groups there is a drop in the yield of HC-PP obtained on reprecipitation (column 5), and the nitrogen and hexosamine contents of the latter are more nearly uniform in the different age groups. Columns 8,9 and 10 show the results of further successive reprecipitations. Instead of nitrogen and hexosamine contents there are given molar nitrogen to hexosamine ratios. These do not change significantly with successive reprecipitations after the first. There does, however, persist a difference between the younger age group. ( 7 to 31 years) and the older age group ( 34 to 74 years). The molar nitrogen to hexosamine ratio in the reprecipitated HC-PP is 50 per cent higher in the product from the older age group than in that from the younger age group, and 100 per cent higher than in the corresponding BN-PP included at the bottom of Table II for comparison.

Multiple extraction procedure. By the single extraction procedure described above, over 20 per cent of the dry weight of the human costal cartilage was extracted and recovered as crude HC-PP. A study was also made to see how much more could be obtained by a series of three successive extractions using the same general extraction procedure. For each experiment about $18 \mathrm{~g}$ of dried cartilage was used. The first extraction was made as described above. For the second extraction the cartilage residue at the stage called $R$ above was used. To the packed residue $(R)$ two volumes of water were added and the mixture was beaten in the VirTis-45 at top speed for one-half hour. Then ethanol was added to bring its concentration to 67 per cent, the mixture was centrifuged at 4,700 $\mathrm{rpm}$ for one-half hour, the supernatant solution was filtered through a glass wool plug and a second yield of crude HC-PP was precipitated from the filtrate by addition of potassium acetate. From the packed cartilage residue of this second extraction, a third extraction was made by the same procedure as for the second. In this

TABLE III

Comparison of human costal cartilage and bovine nasal cartilage with respect to the yields of crude PP obtained in each of three successive extractions *

\begin{tabular}{|c|c|c|c|c|}
\hline \multirow[b]{2}{*}{ Age } & \multicolumn{3}{|c|}{ Human costal cartilage } & \multirow{2}{*}{$\begin{array}{l}\text { Total } \\
\text { yield }\end{array}$} \\
\hline & HC-PP1 & $\mathrm{HC}-\mathrm{PP}_{2}$ & $\mathrm{HC}-\mathrm{PP}_{3}$ & \\
\hline yrs & \multicolumn{3}{|c|}{$\mathrm{g} / \mathrm{g}$ dry cartilage } & \\
\hline 21 & 0.228 & 0.105 & 0.038 & 0.371 \\
\hline 21 & 0.165 & 0.112 & 0.028 & 0.305 \\
\hline 27 & 0.221 & 0.110 & 0.041 & 0.372 \\
\hline 27 & 0.246 & 0.100 & 0.049 & 0.395 \\
\hline 28 & 0.216 & 0.101 & 0.043 & 0.360 \\
\hline 29 & 0.209 & 0.083 & 0.046 & 0.338 \\
\hline 31 & 0.288 & 0.099 & 0.051 & 0.438 \\
\hline 32 & 0.227 & 0.087 & 0.054 & 0.368 \\
\hline 38 & 0.162 & 0.060 & 0.032 & 0.254 \\
\hline \multirow[t]{3}{*}{ Average } & 0.218 & 0.095 & 0.042 & 0.355 \\
\hline & \multicolumn{3}{|c|}{ Bovine nasal cartilage } & \multirow{2}{*}{$\begin{array}{l}\text { Total } \\
\text { yield }\end{array}$} \\
\hline & BN-PP1 & $\mathrm{BN}-\mathrm{PP}_{2}$ & $\mathrm{BN}-\mathrm{PP}_{\mathbf{z}}$ & \\
\hline \multicolumn{5}{|c|}{$g / g d r y$ cartilage } \\
\hline & 0.289 & 0.075 & 0.020 & 0.384 \\
\hline & 0.231 & 0.117 & 0.025 & 0.373 \\
\hline & 0.316 & 0.076 & 0.031 & 0.423 \\
\hline & 0.300 & 0.092 & 0.025 & 0.417 \\
\hline Average & 0.284 & 0.090 & 0.025 & 0.399 \\
\hline
\end{tabular}

* See first page of text for abbreviations. 
way there were obtained three successive yields of crude HC-PP. Table III shows these successive yields in a number of such trials on samples of cartilage from different individuals. For comparison there is also included a similar set of yields from bovine nasal cartilage using the same procedure. It is interesting to note that the spread of values is much higher among the results from human cartilage than among those from bovine cartilage.

\section{RESULTS}

Ultracentrifugal fractionation. After finding that the crude BN-PP could be separated into two fractions by ultracentrifugal means (2), the same method was tried with the crude HC-PP. Essentially the same procedure was used and need not be described in detail here. In Table IV are shown the essential procedures together with the yields of the products for one particular case. The results resembled those found for crude $\mathrm{BN}-\mathrm{PP}$ in that two major fractions could be separated which differed in sedimentation characteristics and each of which contained both protein and polysaccharide. They will therefore be distinguished as heavy $(\mathrm{PP}-\mathrm{H})$ and light ( $\mathrm{PP}-\mathrm{L})$ depending upon the ease with which each sediments. As in all other work done with human costal cartilage, this fractionation was less constant in the proportions of PP-H and PP-L obtained with different samples of crude HC-PP than were the proportions obtained from crude BN-PP. Table V shows the yield of a number of such fractionation experiments, each done with a sample of crude HC-PP of a different individual. The crude HC-PP constituting the first extract from the human costal cartilage on fractionation generally yields amounts of PP-L larger than the amounts of PP-H. The ratio of the average PP-L yield to the average $\mathrm{PP}-\mathrm{H}$ yield is 1.8. This is very different from the corresponding ratio found for the fractionation of crude bovine nasal chondromucoprotein, which is 5.8 (2). Thus the crude PP extracted from human costal cartilage differs from that extracted from bovine nasal septa in containing a smaller proportion of the more readily soluble and less readily sedimentable fraction. Another point of interest brought out in the data of Table $\mathrm{V}$ is that on applying the ultracentrifugal fractionation procedure to each of the three successive crude HC-PP products extracted from human costal

TABLE IV

Steps in the ultracentrifugal separation of crude $H C-P P$ into the two fractions $P P-L$ and $P P-H$ *

\begin{tabular}{|c|c|c|c|}
\hline Step material & Procedure & $\begin{array}{c}\text { Residue } \\
\text { as } \\
\text { loose gel }\end{array}$ & $\begin{array}{c}\text { Product } \\
\text { from } \\
\text { supernatant }\end{array}$ \\
\hline $\begin{array}{l}\text { 1. Crude HC-PP } \\
(3.8 \mathrm{~g})+\end{array}$ & $\begin{array}{l}\text { Stir with VirTis-45 at } 1,000 \mathrm{rpm} \\
15 \mathrm{~min}\end{array}$ & $\begin{array}{l}m l \\
108\end{array}$ & $1.36^{g} \mathrm{PP}-\mathrm{L}$ \\
\hline $\begin{array}{l}0.15 \mathrm{M} \mathrm{KCl} \\
(380 \mathrm{ml})\end{array}$ & Centrifuge at $78,000 \mathrm{G} 2 \mathrm{hrs}$ & & \\
\hline $\begin{array}{l}\text { 2. Gel from step } 1 \\
(108 \mathrm{ml})+\end{array}$ & $\begin{array}{l}\text { Stir with VirTis-45 at } 1,000 \mathrm{rpm} \\
45 \mathrm{~min} ;\end{array}$ & & \\
\hline $\begin{array}{l}0.15 \mathrm{M} \mathrm{KCl} \\
(250 \mathrm{ml})\end{array}$ & $\begin{array}{l}\text { Centrifuge at } 500 \mathrm{G} 20 \mathrm{~min} \text { and } \\
\text { discard residue }(0.14 \mathrm{~g}) ; \\
\text { Centrifuge supernatant solution } \\
\text { at } 78,000 \mathrm{G} 20 \mathrm{~min}\end{array}$ & 84 & 0.80 PP-L \\
\hline $\begin{array}{l}\text { 3. Gel from step } 2 \\
(84 \mathrm{ml})+\end{array}$ & $\begin{array}{l}\text { As step } 2 \text { (discard residue from } \\
\text { centrifuging at } 500 \mathrm{G}, 0.04 \mathrm{~g} \text { ) }\end{array}$ & 60 & 0.14 PP-L \\
\hline $\begin{array}{l}0.15 \mathrm{M} \mathrm{KCl} \\
(350 \mathrm{ml})\end{array}$ & & & \\
\hline $\begin{array}{l}\text { 4. Gel from step } 3 \\
(60 \mathrm{ml})+\end{array}$ & $\begin{array}{l}\text { Stir with VirTis- } 45 \text { at } 1,000 \mathrm{rpm} \\
45 \mathrm{~min} ;\end{array}$ & & \\
\hline $\begin{array}{l}0.15 \mathrm{M} \mathrm{KCl} \\
(400 \mathrm{ml})\end{array}$ & $\begin{array}{l}\text { Centrifuge at } 500 \mathrm{G} 30 \mathrm{~min} \text { and } \\
\text { discard slight residue }\end{array}$ & & 0.99 PP-H \\
\hline
\end{tabular}

* See first page of text for abbreviations.

$\dagger$ In each case the product was precipitated from the supernatant solution by the addition of ethanol ( 2 vol), centrifuged, washed with ethanol and ethyl ether, and dried in vacuo. 
cartilage (as in Table III) there is a progressive fall in the ratio of PP-L to PP-H.

Analytical data for a series of samples of PP-L and $\mathrm{PP}-\mathrm{H}$ prepared from the crude HC-PP from individuals mainly in the age range 20 to 38 years are given in Table VI. To facilitate comparison with previous work done with the analogous products from bovine nasal cartilage, the hexosamine was determined, using galactosamine as a standard. The results for PP-L show a reasonable constancy in the proportion of protein to polysaccharide in products obtained from individuals in the age range 25 to 50 as measured by the molar ratio of nitrogen to galactosamine, while for the few cases in a lower age range the ratio is slightly lower. This ratio, represented by $R_{N / g a l}$ is calculated from the determined percentages of nitrogen and galactosamine by the relation:

$$
\begin{array}{r}
\mathrm{R}_{\mathrm{N} / \mathrm{gal}}=(\% \mathrm{~N} / 14) /(\% \text { galactosamine } / 179)= \\
12.8(\% \mathrm{~N} / \% \text { galactosamine }) .
\end{array}
$$

The average value of this ratio for HC-PP-L is 2.7. Repeated solution of HC-PP-L in $0.1 \mathrm{M} \mathrm{KCl}$, centrifugation at 78,000 G for 1 hour and reprecipitation with 2 vol of ethanol yielded products with this same composition. In contrast to the relative constancy of $\mathrm{R}_{\mathrm{N} / \mathrm{gal}}$ for $\mathrm{HC}-\mathrm{PP}-\mathrm{L}$ there is for $\mathrm{HC}-\mathrm{PP}-\mathrm{H}$ a wider scatter in this ratio, which averages around 8.5. Direct determination

TABLE V

Yields of $P P-L$ and $P P-H$ from crude $H C-P P$ by the

\begin{tabular}{|c|c|c|c|c|c|c|}
\hline \multirow[b]{2}{*}{ Age } & \multicolumn{2}{|c|}{$\mathrm{HC}-\mathrm{PP}_{1}$} & \multicolumn{2}{|c|}{ HC-PP2 } & \multicolumn{2}{|c|}{$\mathrm{HC}-\mathrm{PP}_{3}$} \\
\hline & PP-L & PP-H & PP-L & PP-H & PP-L & PP-H \\
\hline \begin{tabular}{l}
\multicolumn{1}{c}{$y r s$} \\
$0-7$ \\
$0-5$ \\
$19-20$ \\
21 \\
21 \\
29 \\
31 \\
32 \\
32 \\
36 \\
38 \\
$40-50$ \\
50 \\
$72-99$ \\
$60-92$
\end{tabular} & $\begin{array}{l}0.520 \\
0.455 \\
0.500 \\
0.715 \\
0.675 \\
0.523 \\
0.560 \\
0.605 \\
0.394 \\
0.611 \\
0.496 \\
0.430 \\
0.470 \\
0.620 \\
0.610\end{array}$ & $\begin{array}{l}0.200 \\
0.241 \\
0.290 \\
0.341 \\
0.141 \\
0.339 \\
0.319 \\
0.270 \\
0.478 \\
0.195 \\
0.286 \\
0.341 \\
0.175 \\
0.192 \\
0.320\end{array}$ & $\begin{array}{l}0.491 \\
0.353\end{array}$ & $\begin{array}{l}0.248 \\
0.437\end{array}$ & $\begin{array}{l}0.228 \\
0.200\end{array}$ & $\begin{array}{l}0.382 \\
0.505\end{array}$ \\
\hline Average & 0.542 & 0.305 & 0.418 & 0.383 & 0.242 & 0.472 \\
\hline PP-L/PP-H & \multicolumn{2}{|c|}{1.78} & \multicolumn{2}{|c|}{1.09} & \multicolumn{2}{|c|}{0.51} \\
\hline
\end{tabular}
fractionation method of Table $I V^{*}$

* See first page of text for abbreviations.
TABLE VI

Nitrogen and galactosamine content of a series of preparations of PP-L and PP-H from human costal cartilage of sub-

\begin{tabular}{|c|c|c|c|c|c|c|}
\hline \multirow[b]{2}{*}{ Age } & \multicolumn{3}{|c|}{ PP-L } & \multicolumn{3}{|c|}{ PP-H } \\
\hline & $\mathrm{N}$ & $\begin{array}{l}\text { Galact- } \\
\text { osamine }\end{array}$ & $R_{\mathbf{N} / \mathbf{g a l}}$ & $x$ & $\begin{array}{l}\text { Galact- } \\
\text { osamine }\end{array}$ & $\mathbf{R} \times \mathbf{z} \mathbf{s} 1$ \\
\hline yrs & $\%$ & $\%$ & & $\%$ & $\%$ & \\
\hline $0-5$ & 4.9 & 29.0 & 2.1 & 9.2 & 18.2 & 6.5 \\
\hline $19-25$ & 5.0 & 26.2 & 2.4 & 9.3 & 17.1 & 7.0 \\
\hline 21 & 5.1 & 28.4 & 2.3 & 10.5 & 16.6 & 8.1 \\
\hline $26-28$ & & 28.0 & & 10.1 & 15.2 & \\
\hline $26-28$ & 5.4 & 25.9 & 2.6 & & & \\
\hline 28 & 5.9 & 27.9 & 2.8 & 10.8 & 14.3 & 9.6 \\
\hline 28 & 5.9 & 28.0 & 2.7 & & & \\
\hline 28 & 6.3 & 28.2 & 2.9 & 11.1 & 12.5 & 11.4 \\
\hline 28 & 5.9 & 25.8 & 2.9 & 11.1 & 15.3 & 9.3 \\
\hline 29 & 6.2 & 28.6 & 2.8 & 10.4 & 15.4 & 8.7 \\
\hline 31 & 5.6 & 28.2 & 2.5 & 10.2 & 16.8 & 7.8 \\
\hline 31 & 5.8 & 27.2 & 2.7 & 8.9 & 16.2 & 7.0 \\
\hline 36 & 5.6 & 25.1 & 2.8 & 9.3 & 17.2 & 6.9 \\
\hline 36 & 5.8 & 26.3 & 2.8 & 10.4 & 17.7 & 7.5 \\
\hline & 5.8 & 26.2 & 2.8 & 11.9 & 12.8 & 11.9 \\
\hline 50 & 6.1 & 25.2 & 3.0 & & & \\
\hline Average & 5.7 & 27.1 & 2.7 & 10.2 & 15.8 & 8.5 \\
\hline
\end{tabular}
jects of various ages *

* All samples indicated by a single age were from one individual; samples indicated by an age range were made from crude HC-PP pooled from several individuals of ages within the indicated range. See first page of text for abbreviations.

of protein by the biuret method gave 21 per cent protein in PP-L, and 66 per cent protein in PP-H. Both these values are higher than those for the corresponding proteinpolysaccharides of bovine nasal cartilage.

Solutions of HC-PP-L in water are clear enough so that optical rotations can be measured. Determinations of two separate samples gave values for $[\alpha]_{\mathrm{D}}, 1$ per cent in water, $-24.2^{\circ}$ and $-26.4^{\circ}$. On the other hand, solutions of $\mathrm{HC}$ PP-H are extremely opalescent.

\section{DISCUSSION}

The work presented shows that the methods developed for the isolation of the proteinpolysaccharides from bovine nasal septa are applicable to human costal cartilage and give results roughly parallel but differing in detail. A crude HC-PP analogous to crude $\mathrm{BN}-\mathrm{PP}$ (earlier called chondromucoprotein) can be isolated in somewhat lower yields and with a generally higher protein content and also a more variable composition with regard to the proportion of protein and polysaccharide (Table I). The crude HC-PP also differs from the crude $\mathrm{BN}-\mathrm{PP}$ in that after a single 
reprecipitation its composition is changed, particularly with material from persons over 30 years old, in the direction of a decreased proportion of protein to polysaccharide. On further reprecipitation there is no significant further change in composition (Table II). The total amount of such crude proteinpolysaccharide that can be isolated by a series of three successive extractions from a sample of human costal cartilage amounts to 35 per cent of the dry weight of the cartilage, while a similar triple extraction of bovine nasal cartilage yields a total of 40 per cent of its dry weight (Table III).

The method developed for the ultracentrifugal fractionation of crude $\mathrm{BN}-\mathrm{PP}$ is also applicable to crude HC-PP. Two clear-cut fractions can be obtained, an easily sedimentable fraction (HC$\mathrm{PP}-\mathrm{H})$ and a less readily sedimentable fraction (HC-PP-L). The yields of each of these fractions varies rather widely with the individual from whom the crude chondromucoprotein was obtained (Table V). Just as the crude HC-PP has a higher protein content than BN-PP, so both $\mathrm{HC}-\mathrm{PP}-\mathrm{L}$ and $\mathrm{HC}-\mathrm{PP}-\mathrm{H}$ have higher protein contents than their bovine analogs BN-PP-L and BN-PP-H (Table VI).

In the case of bovine nasal cartilage it was shown that, on treatment with alkali, both PP-L and $\mathrm{PP}-\mathrm{H}$ yield chondroitin sulfate with the same optical rotation, $[\alpha]_{D}=-24^{\circ}$. With the products from human costal cartilage, greater difficulty was encountered in this as in all other procedures and the results cannot yet be reported. Work of Meyer, Hoffman and Linker (3) and Kaplan and Meyer (4) indicates that both chondroitin sulfates $\mathrm{A}$ and $\mathrm{C}$ and keratosulfate are found in human costal cartilage. It is now of importance to find which of these is in the PP-L or $\mathrm{PP}-\mathrm{H}$ and which remains in the cartilage residue, for this residue contains about one-half of the hexosamine of the original human costal cartilage.
The amount of hexosanine left in the bovine nasal cartilage residue after extraction of the crude $\mathrm{BN}-\mathrm{PP}$ is only about 20 per cent of that originally present.

With the successive improvements reported in the isolation and fractionation of the proteinpolysaccharides of cartilage, it begins to be feasible to attack a problem of concern in the rheumatic diseases: the amount and condition of the proteinpolysaccharides in cartilages, particularly the articular cartilage, of rheumatic patients.

\section{SUMMARY}

Using the extraction procedure developed for use with bovine nasal cartilage, a study of human costal cartilage has been made. By three successive extractions with water, crude proteinpolysaccharide can be isolated in amounts of 20 to 35 per cent of the dry weight of the cartilage. While similar in properties to the crude proteinpolysaccharide reported from bovine nasal cartilage, the corresponding product from human costal cartilage contains more protein and less polysaccharide. Ultracentrifugal fractionation at $78,000 \times \mathrm{G}$ resulted in separation of this crude product into a rapidly sedimenting fraction and a nonsedimenting fraction. Yields and analytical data on these products are given. Both fractions contain more protein than do the corresponding fractions made from bovine nasal cartilage.

\section{REFERENCES}

1. Malawista, I., and Schubert, M. Chondromucoprotein; new extraction method and alkaline degradation. J. biol. Chem. 1958, 230, 535.

2. Gerber, B. R., Franklin, E. C., and Schubert, M. Ultracentrifugal fractionation of chondromucoprotein. J. biol. Chem. In press.

3. Meyer, K., Hoffman, P., and Linker, A. Mucopolysaccharides of costal cartilage. Science 1958, 128, 896.

4. Kaplan, D., and Meyer, K. Ageing of human cartilage. Nature (Lond.) 183, 1267. 